\title{
Silent Brain Infarction and Blood Fibrinogen Level in Patients with Obstructive Sleep Apnea Syndrome (Cross Sectional Study)
}

A.A.Khodair, M.M.Omar, M.K.Faheem, Sh.M. Kasem and A.M.Nagah

Neuopsychaitry Dept., Faculty of Medicine, Benha Univ., Benha, Egypt

E-Mail: ahmedsaltoh2018@yahoo.com

\begin{abstract}
Obstructive sleep apnea (OSA) is a form of sleep disordered breathing with a high prevalence rate and OSA is associated with hypertension, coronary artery disease, stroke, peripheral vascular disease, heart failure and arrhythmias. The occurrence of stroke in patients with OSA is likely preceded by subclinical cerebrovascular disease, often termed "silent brain infarction" (SBI), which is detectable with brain magnetic resonance imaging (MRI). chronic nighttime hypoxemia and sleep disturbances in OSA patients may lead to elevated proinflammatory cytokines, markers of inflammation and plasma fibrinogen levels.

This study was conducted to detect the occurance of silent cerebral infarction and measure the fibrinogen level in patients with obstructive sleep apnea syndrome (OSAS).

This study was carried out in chest department in Benha University Hospital, it was conducted on 170 patients presented with OSA, Polysomnography, plasma fibrinogen level measurement and brain MRI were done for each patient.
\end{abstract}

Keywords: Silent brain infarction, Blood fibrinogen level and obstructive sleep apnea syndrome.

\section{Introduction}

Quiet cerebrum localized necrosis (SBI) need been depicted Likewise cerebrum infarcts that are watched on Possibly registered tomographic or mri filters in the nonattendance about whatever corresponding, clinically evident cerebrovascular ischemic occasion [1].

Obstructive rest apnea (OSA) will be An structure from claiming rest confused relaxing with a secondary pervasiveness rate and OSA is connected with hypertension, coronary vein disease, stroke, fringe vascular disease, heart disappointment What's more arrhythmias [2].

Obstructive rest apnea hypopnea syndrome (OSAHS), an underdiagnosed state that influences give or take 5\% of the general population, is portrayed Toward repeater upper aviation route obstacle Throughout rest Furthermore indications connected with. Unrefreshing rest. OSAHS, a underdiagnosed condition that influences pretty nearly $5 \%$ of the general population, is described Eventually Tom's perusing repeater upper aviation route hindrance Throughout rest and side effects connected with unrefreshing rest [3].

Those event of stroke for patients with OSA may be liable preceded Toward subclinical cerebrovascular disease, frequently all the termed "silent mind infarction" (SBI), which will be perceivable with cerebrum mri [4].

There need aid a few instruments Toward which OSA might build the hazard of stroke. Person likelihood is that cerebral blood stream speed will be diminished by those negative intrathoracic weight that is commonly produced Throughout an obstructive apnea. Alternatively, cerebrovascular late reactions to hypoxia in patients for OSA might be diminished because of irregular hypoxia, oxiᄀdant-mediated endothelial dysfunction, expanded thoughtful activity, Also impeded cerebral vasomotor light of carbon dioxide [5].

Fibrinogen, An plasma protein synthesized in the liver, will be personally included clinched alongside blood coagulation. Fibrinogen is likewise an acute-phase protein, expanding because of the opposition to contamination Also aggravation [6].

Fibrinogen enhances thrombosis and atherosclerosis Eventually Tom's perusing impacts ahead platelet aggregation, blood rheology Also endothelial Mobile damage [7].

OSA brings about tedium Furthermore extreme nighttime hypoxemia Also rest disturbances [8]. Hypoxemia during secondary height makes expanded union for both fibrinogen [9] Also. cytokines [10]. Sleep deprivation also induces an increase in cytokines [11] Thus, both chronic nighttime hypoxemia and sleep disturbances in OSA patients may lead to elevated proinflammatory cytokines, markers of inflammation and plasma fibrinogen levels.

\section{Patients and methods}

This may be a cross sectional consider conveyed out in midsection division for Benha school Hospital, between february 2017 Furthermore january 2019. It included 170 patients of OSA satisfying the Incorporation criteria.

Incorporation criteria:. Instances with obstructive rest apnea more than 18 a considerable length of time old, both guys Also females are incorporated \& acknowledge 
to provide for assent on be included in the contemplate.

Avoidance criteria:. Patients for history about cerebrovascular stroke.

Patients for vital rest apnea.

Patients for blended rest apnea.

Comorbid incendiary ailments (eg: SLE, rheumatoid arthritis).

Comorbid spoiling.

Patients for renal or hepatic impedance.

Patients unabated or deny with provide for formal assent.

Regard about moral council might have been finished Also every one from claiming patients were subjected of the accompanying methods then afterward bringing their consent:. restorative history.

- physical and neurological examinations.

- Polysomnography In the rest lab of the midsection division from claiming our employees about solution on affirm the finding from claiming OSA. An overnight polysomnography will make performed with nonstop following Eventually Tom's perusing An rest technicolor. The framework comprises from claiming 6 channels from claiming eeg Furthermore 2 channels for EOG, recording submental EMG, oronasal air flow, thoracic and abdominal movements, ECG, pulse oximeter oxygen saturation, tibial EMG\& particular figure position.

- lab investigations:. Complete blood check.

Irregular glucose level.

Serum electrolytes level (Na, K, Ca).

Liver capacity test (AST, ALT, albumin, bilirubin).

Kidney work test (urea, creatinine \&uric acid).

Lipid profile (TG, cholesterol).

Indicators for aggravation Likewise TLC, rh component Furthermore esr.

Plasma fibrinogen level measurement: $2 \mathrm{ml}$ from claiming venous blood will be gathered from patients for a anticoagulant (sodium citrate) under complete aseptic states over sterile tubes, centrifuged will differentiate those plasma afterward plasma fibrinogen level will a chance to be measured Eventually Tom's perusing fibrinogen test kits.

-Radiological: mind mri (T1-WI, T2-WI \& style images).

\section{Statistical analysis}

Data management and statistical analysis were done using SPSS vs.16. (SpssInc, Chicago, ILL Company).

Categorical data was summarized as numbers and percentages using "chi square" or " $Z$ " test for analyzing them. Continuous variables were presented as mean and standard deviation using "Student $\mathrm{t}$ " test for analyzing them, or median and range using Mann Whitney U test for them. Other suitable tests of significance as correlation coefficients were used when indicated according to the situation. The accepted level of significance in this work was $0.05, \quad(\mathrm{P}<0.05$ will be considered significant).

Logistic regression analysis was done for prediction of SBI. Odds ratios with $95 \%$ confidence intervals were calculated for predictors.

\section{Results}

Those average period to instances for SBI "around those examined example is 60 a considerable length of time \& this will be statistically Exceptionally significant, Additionally reveals to that females for SBI "around those mulled over test are 56. 2\% contrasted with the guys with danger to have SBI 1. 7 times Likewise those guys. The hypertension is statistically critical danger element for SBI Around the concentrated on example expanding defenselessness to have SBI Toward 2. 14 times contrasted with cases without hypertension, likewise $\mathrm{dm}$ may be Exceedingly critical hazard variable expanding powerlessness will bring SBI by 5. 8 times contrasted with situations without $\mathrm{dm}$.

However, BMI \& smoking auto are not noteworthy danger figure to SBI "around the concentrated on example Table (1).

The median minimal $\mathrm{O} 2$ saturation for cases with SBI among the studied sample is $76 \%$ with range between $56 \& 90 \%$ and the median of sum of all desaturations is $30 \%$, both are statistically highly significant. Table (2).

The median minimal $\mathrm{O} 2$ saturation for cases with high fibrinogen level among the studied sample is $76 \%$ \& this is highly significant, also the median of all desaturations for these cases is $30 \% \&$ this is highly significant Table (3).

\section{Discussion}

Obstructive rest apnea (OSA) need been embroiled to both cardiovascular Furthermore cerebrovascular ailments. Systemic aggravation What's more coagulation might be identified with cardiovascular pathophysiology for patients for OSA. Fibrinogen is a significant coagulation protein connected with aggravation Also long haul raised plasma fibrinogen is connected with an expanded hazard for significant cardiovascular sicknesses [12]. 
The event from claiming stroke On patients with OSA will be prone preceded Toward subclinical cerebrovascular disease, frequently termed "silent mind infarction" (SBI), which is perceivable with mind mri [4].

This investigation may be a cross sectional contemplate directed looking into midsection Branch from claiming Benha school doctor's facility pointed with recognize the occurance for quiet cerebral localized necrosis What's more measure those fibrinogen level for patients with obstructive rest apnea syndrome (OSAS).

The contemplated example might have been 170 patients about OSA satisfying those Incorporation criteria.

In this investigation the average period to situations with SBI Around the contemplated example might have been 60 A long time which might have been statistically Exceedingly noteworthy. This result might have been in understanding with [13] who news person that those agdistis need been a standout amongst those The majority plainly distinguished danger figures to SBI \& with(14) who expressed that those more seasoned those investigated population, those higher the danger of SBI event.

In this investigation those females with SBI "around those mulled over test were 56. $2 \%$ contrasted with the guys for danger to have SBI 1. 7 times contrasted with those guys. This come about might have been in contradiction for [15] who found that ladies for OSA were during lesquerella long haul danger about Creating stroke alternately hypertension due to sex contrasts to vital chemoreflex affectability when up and about and apnea edge with rest.

However, [16] found that those companionship between SBI \& sexual orientation might have been vague.

In this study the hazard for SBI expanded with $\mathrm{BMI} \geq 29 \&$ this aftereffect might have been in understanding for [17] who distinguished expanded danger to SBI for An $\mathrm{BMI} \geq 25 \mathrm{~kg} / \mathrm{m} 2$.

However, [18] accounted for sure Acquaintanceship the middle of OSA Also SBI in the 65-year age class in the non-obese members.

[16] discovered that those cooperation between SBI \& stoutness might have been likewise vague.

In this ponder smoking auto might have been not viewed as as An critical hazard component for SBI "around the examined example. This come about might have been in understanding for [16] who discovered that the Acquaintanceship between SBI \& smoking auto might have been vague.
However, [19] accounted that the individuals who smoked haddock required additional SBI. Also, [20] inferred that smoking auto might have been also a critical variable concerning SBI to elderly individuals.

In this consider those hypertension might have been statistically noteworthy danger element to SBI Around those mulled over example expanding defenselessness on. Have SBI Toward 2. 14 times contrasted with situations without hypertension. This aftereffect might have been in understanding with [16] who accounted An solid cooperation the middle of SBI \& hypertension.

In this study dm might have been An Exceptionally noteworthy hazard element expanding defenselessness should need SBI by 5. 8 times contrasted with situations without $\mathrm{dm}$.

This result might have been in understanding for [21] who found noteworthy Acquaintanceship the middle of SBI \& dm.

However, (16) found that those affiliation the middle of SBI \& dm might have been vague.

In this contemplate the average negligible $\mathrm{O} 2$ immersion to instances for SBI "around those contemplated test might have been $76 \%$ with reach between $56 \& 90 \%$ and the average for entirety for the sum desaturations might have been $30 \%$ for reach the middle of 5-65\%, both were Exceedingly critical to Creating SBI for patients with OSA.

This aftereffect might have been in understanding for [4] who portrayed that those patients with quiet cerebrum infarcts have additional oxygen desaturation scenes over patients without What's more this might help expansion those harm to little cerebrum vessels, favouring An speedier improvemen for arteriolosclerosis and the manifestation from claiming lacunar infarctions.

Also, suitably for [22] who accounted that hypoxia might intervene expands clinched alongside systemic aggravation Furthermore platelet actuation and increment those hazard of Creating SBI for OSA.

In addition, [23] found a sure cooperation between SBI and the nighttime oxygen desaturation to OSA.

In this study those average negligible $\mathrm{O} 2$ immersion to cases for secondary fibrinogen level "around those mulled over example might have been $76 \%$ for extent between 56$90 \%$ and the average of the greater part desaturations to these situations might have been $30 \%$ with range between $2 \& 156$ which might have been statistically Exceedingly noteworthy. 
This effect might have been in understanding with [12] who found that those rise of fibrinogen levels is conversely identified with mean $\mathrm{O} 2$ immersion What's more most reduced $\mathrm{O} 2$ immersion.
Also, in understanding with [9] who discovered that the rise for plasma fibrinogen levels done OSA patients may be identified with hypoxic states happening Throughout rehashed apneic

occasions.

Table (1) Relation between SBI and socio-demographic characters.

\begin{tabular}{|c|c|c|c|c|c|c|c|}
\hline \multicolumn{2}{|l|}{ Variable } & \multicolumn{2}{|c|}{$\begin{array}{l}\text { No SBI } \\
(n=87)\end{array}$} & \multicolumn{2}{|c|}{$\begin{array}{l}\text { SBI } \\
(n=83)\end{array}$} & $\mathrm{Z}_{\mathrm{MWU}}$ test & $\mathbf{P}$ \\
\hline Age (ys) & $\begin{array}{l}\text { Median } \\
\text { (Range) }\end{array}$ & & & & 87) & 5.06 & $<0.001$ (HS) \\
\hline BMI $\left(\mathrm{kg} / \mathrm{m}^{2}\right)$ & Median & & & & 59) & 1.44 & $0.15(\mathrm{NS})$ \\
\hline Sex & $\begin{array}{c}\text { Male } \\
\text { Female }\end{array}$ & $\begin{array}{c}\text { No. } \\
52 \\
35\end{array}$ & $\begin{array}{c}\% \\
57.8 \\
43.8\end{array}$ & $\begin{array}{l}\text { No. } \\
38 \\
45\end{array}$ & $\begin{array}{c}\% \\
42.2 \\
56.2\end{array}$ & $\begin{array}{c}\chi^{2}(\mathrm{P}) \\
3.3 \\
(0.068)\end{array}$ & $\begin{array}{c}\text { OR }(95 \% \mathrm{CI}) \\
1.7 \\
(0.96-3.2)\end{array}$ \\
\hline $\begin{array}{l}\text { Smoking }(\mathrm{n}=90 \\
\text { males) }\end{array}$ & $\begin{array}{l}\text { No } \\
\text { Yes }\end{array}$ & $\begin{array}{l}14 \\
38\end{array}$ & $\begin{array}{l}46.7 \\
63.3\end{array}$ & $\begin{array}{l}16 \\
22\end{array}$ & $\begin{array}{l}53.3 \\
36.7\end{array}$ & $\begin{array}{l}2.27 \\
(0.13)\end{array}$ & $\begin{array}{c}0.51 \\
(0.21-1.2)\end{array}$ \\
\hline Hypertension & $\begin{array}{l}\text { No } \\
\text { Yes }\end{array}$ & $\begin{array}{l}52 \\
35\end{array}$ & $\begin{array}{l}60.5 \\
41.7\end{array}$ & $\begin{array}{l}34 \\
49\end{array}$ & $\begin{array}{l}39.5 \\
58.3\end{array}$ & $\begin{array}{c}6.01 \\
(0.014, \mathrm{~S})\end{array}$ & $\begin{array}{c}2.14 \\
(1.16-3.95)\end{array}$ \\
\hline DM & $\begin{array}{l}\text { No } \\
\text { Yes }\end{array}$ & $\begin{array}{c}81 \\
6\end{array}$ & $\begin{array}{l}58.3 \\
19.4\end{array}$ & $\begin{array}{l}58 \\
25\end{array}$ & $\begin{array}{l}41.7 \\
80.6\end{array}$ & $\begin{array}{c}15.3 \\
(<0.001 \\
\text { HS })\end{array}$ & $\begin{array}{c}5.8 \\
(2.2-15.1)\end{array}$ \\
\hline & & $\mathrm{SB}$ & $\begin{array}{l}\text { Diab } \\
\text { Bod } \\
\text { ent }\end{array}$ & $\begin{array}{l}\text { n Whi } \\
\text { Mellitu } \\
\text { ss inde } \\
\text { infarct }\end{array}$ & test & & \\
\hline
\end{tabular}

Table (2) Relation between $\mathrm{SBI}$ and $\mathrm{O}_{2}$ saturations.

\begin{tabular}{|c|c|c|c|c|c|c|}
\hline \multirow[t]{2}{*}{ Variable } & \multicolumn{2}{|c|}{$\begin{array}{c}\text { No SBI } \\
(n=87)\end{array}$} & \multicolumn{2}{|c|}{$\begin{array}{c}\text { SBI } \\
(n=83)\end{array}$} & \multirow[t]{2}{*}{$\mathrm{Z}_{\mathrm{MWU}}$ test } & \multirow[t]{2}{*}{$\mathbf{P}$} \\
\hline & Median & Range & Median & Range & & \\
\hline $\begin{array}{l}\text { Minimal } \mathrm{O}_{2} \\
\text { saturations }\end{array}$ & 86.0 & $56-94$ & 76.0 & $56-90$ & 5.54 & $\begin{array}{l}<0.001 \\
(\mathrm{HS})\end{array}$ \\
\hline $\begin{array}{l}\text { Sum of all de } \\
\text { saturations }\end{array}$ & 11.0 & $2-156$ & 30.0 & $5-65$ & 5.12 & $\begin{array}{c}<0.001 \\
(\mathrm{HS})\end{array}$ \\
\hline
\end{tabular}

SBI: Silent brain infarction.

Table (3) Relation between fibrinogen level and $\mathrm{O}_{2}$ saturations.

\begin{tabular}{|c|c|c|c|c|c|c|}
\hline \multirow[t]{2}{*}{ Variable } & \multicolumn{2}{|c|}{ Fibrinogen $<350(n=73)$} & \multicolumn{2}{|c|}{$\begin{array}{l}\text { Fibrinogen }>350 \\
(n=97)\end{array}$} & \multirow[t]{2}{*}{$\mathrm{Z}_{\mathrm{MWU}}$ test } & \multirow[t]{2}{*}{$\mathbf{P}$} \\
\hline & Median & Range & Median & Range & & \\
\hline $\begin{array}{l}\text { Minimal } \mathrm{O}_{2} \\
\text { saturations }\end{array}$ & 88.0 & $58-94$ & 76.0 & $56-90$ & 5.54 & $\begin{array}{l}<0.001 \\
(\mathrm{HS})\end{array}$ \\
\hline $\begin{array}{l}\text { Sum of all de- } \\
\text { saturations }\end{array}$ & 10.0 & $2-62$ & 30.0 & $2-156$ & 5.12 & $\begin{array}{l}<0.001 \\
(\mathrm{HS})\end{array}$ \\
\hline
\end{tabular}

\section{Conclusion}

There is a positive correlation between SBI $\&$ OSA. Patients with SBI and OSA have elevated fibrinogen levels which correlate positively with indices of sleep apnea severity.
The related increase in coagulation activity and vasoreactivity may represent a possible pathophysiological mechanism behind the increased vascular morbidity of patients with OSA. 


\section{References}

[1] YC.Zhu, C. Dufouil , C.Tzourio and H. Chabriat, Silent brain infarcts: a review of MRI diagnostic criteria Stroke, Vol.42,PP.1140-5,2011

[2] Fatima H. Sert Kuniyoshi, Snigdha Pusalavidyasagar, Prachi Singh \& Virend K. Somers, Division of Cardiovascular Diseases, Department of Internal Medicine, Division of Sleep Medicine, University of Minnesota Medical Center, Vol.131, PP. 196-205,2009.

[3] Miguel A. Arias and Adria'n Baranchuk, Atrial Fibrillation and Obstructive Sleep Apnea: Something More Than a Coincidence. Rev Esp Cardiol., Vol. 66(7), PP.529-531, 2013.

[4] José Alvarez-Sabín, Odile Romero ,Pilar Delgado, Manuel Quintana, Estevo Santamarina, Alex Ferré, Olga Maisterra,Iolanda Riba-Llena, Joan Montaner and Gabriel Sampol, Obstructive sleep apnea and silent cerebral infarction in hypertensive individuals, Vol.66, PP.77-80,2018.

[5] AE.Beaudin, M.ssPun, C.Yang , DD.Nicholl , CD.Steinback , DM.Slater , KE.Wynne-Edwards ,PJ. Hanly, SB.Ahmed and MJ.Poulin, Cyclooxygenases 1 and 2 differentially regulate blood pressure and cerebrovascular responses to acute and chronic intermittent hypoxia: implications for sleep apnea. J Am Heart Assoc., Vol.3, PP.875-877,2014.

[6] Thomas E. Wessendorf, Alfred F. Thilmann, You-Ming Wang, Andreas Schreiber, Nikolaus Konietzko and Helmut Teschler, Fibrinogen Levels and Obstructive Sleep Apnea in Ischemic Stroke. PubMed: 11112110,Vol.7, PP.3437,2000.

[7] Eber B and Schumacher M. (1993): fibrinogen; its role in the hemostatic regulation in atherosclerosis. SeminThrombHemost., Vol.51, PP.5660,1993 .

[8] Agata Gabryelska, Zuzanna M. Łukasik, Joanna S. Makowska and Piotr Białasiewicz, Obstructive Sleep Apnea: From Intermittent Hypoxia to Cardiovascular Complications via Blood Platelets, Vol. 9,PP. 635-637,2018.

[9] R.Imoberdorf, PJ.Garlick, MA.McNurlan, GA. Casella, E.Peheim, M.Turgay, P.Bartsch and PE.Ballmer ,Enhanced synthesis of albumin and fibrinogen at high altitude. J ApplPhysiol, Vol. 90(2), PP.528-537,2001.

[10] G.Hartmann, M.Tschop, R.Fischer ,
C.Bidlingmaier ,R. Riepl , K.Tschop , H.Hautmann , S.Endres and M.Toepfer, High altitude increases circulating interleukin-6, interleukin-1 receptor antagonist and C-reactive protein. Cytokine, Vol.12(3), PP. 246252,2000.

[11] AN.Vgontzas, DA.Papanicolaou, EO.Bixler, A.Lotsikas, K.Zachman, A.Kales, P.Prolo, ML.Wong, J.Licinio, PW.Gold, RC.Hermida, G.Mastorakos and GP.Chrousos, Circadian interleukin-6 secretion and quantity and depth of sleep. J Clin Endocrinol Metab.,Vol.84(8),PP.2603-2607,1999.

[12] Abu Shamsuzzaman, Raouf S. Amin, Andrew D. Calvin, Diane Davison and Virend K. Somers, Severity of Obstructive Sleep Apnea is Associated with Elevated Plasma Fibrinogen in Otherwise Healthy Patients, Vol.162, PP.82-86,2014.

[13] K.Fukuda, Y.Takashima, M.Hashimoto, A.Uchino, T.Yuzuriha and H.Yao, Early menopause and the risk of silent brain infarction in community-dwelling elderly subjects: the Sefuri Brain MRI Study. J Stroke CerebrovascDis., Vol.23, PP.817$822,2014$.

[14] K.Inoue, M.Matsumoto, T.Shono, S.Toyokawa and A.Moriki, Increased intima media thickness and atherosclerotic plaques in the carotid artery as risk factors for silent brain infarcts. $\mathbf{J}$ Stroke CerebrovascDis., Vol. 16, PP.14-20,2007.

[15] John S. Floras, Sleep Apnea and Cardiovascular Disease An Enigmatic Risk Factor CircRes., Vol.122, PP.1741$1764,2018$.

[16] Jonathon P Fanning, Andrew A Wong and John F Fraser, The epidemiology of silent brain infarction: a systematic review of population-based cohorts, BMC Medicine, Vol. 12, PP.119-122,2014.

[17] H.Bokura, S.Yamaguchi, K.Iijima, A.Nagai and H. Oguro, Metabolic syndrome is associated with silent ischemic brain lesions. Stroke, Vol.39, PP.16079,2008

[18] Eo Rin Cho, Hyun Kim, Hyung Suk Seo, Sooyeon Suh, Seung Ku Lee and Chol Shin, Obstructive sleep apnea as a risk factor for silent cerebral infarction. J SleepRes., Vol.22, PP.452-458,2013.

[19] M.Serizawa, T.Nabika, Y.Ochiai et al., Association between PRKCH gene polymorphisms and subcortical silent brain infarction. Atherosclerosis, Vol. 199, PP.340-5,2008.

[20] Y.Takashima, Y.Miwa, T.Mori et al.,Sex 
differences in the risk profile and male predominance in silent brain infarction in community-dwelling elderly subjects: the Sefuri brain MRI study. HypertensRes., Vol.33, PP.748-52,2010.

[21] Kwon HM, Kim BJ, Lee SH, Choi SH, Oh BH, Yoon BW. (2006): Metabolic syndrome as an independent risk factor of silent brain infarction in healthy people. Stroke 2006; 37:466-70.

[22] K.Minoguchi, T.Yokoe, T.Tazaki, H.Minoguchi, N.Oda, A.Tanaka, M.Yamamoto, S.Ohta, CP.O'Donnell and
M.Adachi, Silent brain infarction and platelet activation in obstructive sleep apnea. Am J RespirCritCareMed., Vol.175, PP.612-17,2007.

[23] K.Eguchi, K.Kario and S.Hoshide , Nocturnal hypoxia is associated with silent cerebrovascular disease in a highrisk Japanese community dwelling population. American Journal of Hypertension., Vol.18(11), PP. 14891495,2005 . 